\title{
Delivery as nanoparticles reduces imatinib mesylate-induced cardiotoxicity and improves anticancer activity
}

This article was published in the following Dove Press journal:

International Journal of Nanomedicine

24 April 2015

Number of times this article has been viewed

\author{
Gregory Marslin' \\ Ann Mary Revina ${ }^{2,3}$ \\ Vinoth Kumar Megraj \\ Khandelwal ${ }^{4}$ \\ Krishnamoorthy Balakumar ${ }^{5}$ \\ Jose Prakash ${ }^{6}$ \\ Gregory Franklin ${ }^{1, *}$ \\ Caroline J Sheeba ${ }^{2,3,7, *}$
}

'AgroBioPlant Group, Centre for the Research and Technology of Agro-Environment and Biological Sciences (CITAB), University of Minho, Braga, Portugal; ${ }^{2}$ Life and Health Sciences Research Institute (ICVS), School of Health Sciences, University of Minho, Braga, Portugal; 3ICVS/3B's - PT Government Associate Laboratory, Braga/ Guimarães, Portugal; ${ }^{4}$ Department of Translational Pharmacology, Consorzio Mario Negri Sud, Santa Maria Imbaro, Italy; ${ }^{5}$ Department of Pharmaceutics, PSG College of Pharmacy, Coimbatore, Tamil Nadu, India; ${ }^{6}$ Department of Pharmaceutics, Vels University, Chennai, Tamil Nadu, India; ${ }^{7}$ Regenerative Medicine Program, Department of Biomedical Sciences and Medicine, University of Algarve, Faro, Portugal

*These authors contributed equally to this work

Correspondence: Gregory Franklin AgroBioPlant Group, Centre for the Research and Technology of Agro-Environment and Biological Sciences (CITAB), University of Minho, 47 I0-057 Braga, Portugal

Tel +35 I 253604865

Fax +35I 253604809

Email franklin@bio.uminho.pt

\begin{abstract}
Clinical effectiveness of imatinib mesylate in cancer treatment is compromised by its off-target cardiotoxicity. In the present study, we have developed physically stable imatinib mesylate-loaded poly(lactide-co-glycolide) nanoparticles (INPs) that could sustainably release the drug, and studied its efficacy by in vitro anticancer and in vivo cardiotoxicity assays. MTT (methylthiazolyldiphenyl-tetrazolium bromide) assay revealed that INPs are more cytotoxic to MCF-7 breast cancer cells compared to the equivalent concentration of free imatinib mesylate. Wistar rats orally administered with $50 \mathrm{mg} / \mathrm{kg}$ INPs for 28 days showed no significant cardiotoxicity or associated changes. Whereas, increased alanine aminotransferase, aspartate aminotransferase, and alkaline phosphatase levels, and reduced white blood cell, red blood cell, and hemoglobin content were observed in the animals administered with free drug. While the histological sections from hearts of animals that received INPs did not show any significant cardiotoxic symptoms, loss of normal architecture and increased cytoplasmic vacuolization were observed in the heart sections of animals administered with free imatinib mesylate. Based on these results, we conclude that nano-encapsulation of imatinib mesylate increases its efficacy against cancer cells, with almost no cardiotoxicity.
\end{abstract}

Keywords: imatinib nanoparticles, cytotoxicity, cardiotoxicity, hematology

\section{Introduction}

Overexpression of receptor tyrosine kinase is a common mechanism associated with multiple malignancies. ${ }^{1}$ Imatinib mesylate is a tyrosine kinase inhibitor, which typically blocks the tyrosine kinase activity of BCR-Abl, ${ }^{2}$ platelet-derived growth factor receptors (PDGFRs), ${ }^{3}$ and $\mathrm{KIT}^{4}$ proteins, forming the basis of its use in the treatment of chronic myelogenous leukemia (CML) and gastrointestinal stromal tumors (GISTs). In CML, the characteristic reciprocal translocation between chromosomes results in the derivative Philadelphia chromosome, with the BCR-Abl fusion gene that produces the BCR-Abl hybrid protein, possessing constitutive tyrosine kinase activity. Imatinib mesylate is used to inhibit BCR-Abl from phosphorylating other proteins that are involved in the pathogenesis of CML. ${ }^{5,6}$ In the case of GISTs, the underlying mechanism is a gain-of-function mutation in c-kit or PDGFR $\alpha$ genes, causing the production of abnormal KIT and PDGFR $\alpha$ receptors that induce uncontrolled cell growth and cell division. Imatinib mesylate specifically antagonizes the intracellular adenosine triphosphate (ATP)-binding sites of these receptors, making it a leading drug in the treatment of GISTs. ${ }^{7}$

BCR-Abl hybrid protein only exists in cancer cells and not in healthy cells. However, KIT and PDGFR are also expressed in normal cells, where they perform 
crucial roles in hematopoiesis, blood vessel formation, and vasculature maintenance. ${ }^{8,9}$ PDGFRs are also known to be involved in the response of endothelial and smooth muscle cells to injury and other stressors in the cardiovascular system. ${ }^{10}$ In this context, employing a tyrosine kinase inhibitor like imatinib mesylate to treat cancer has been reported to cause unanticipated cardiotoxicity. ${ }^{11-14}$ For instance, imatinib mesylate-treated male spontaneously hypertensive rats are reported to present cardiac lesions, characterized by cytoplasmic vacuolization and myofibrillar loss, suggesting a correlation between hypertension and imatinib mesylate-induced cardiotoxicity. ${ }^{12}$ More recently, the deleterious effect of imatinib mesylate on the heart was shown to be dose-, time-, and age-dependent. ${ }^{14}$ These authors found mitochondrial impairment and cell death as the mechanisms of myocyte loss and cardiac dysfunction, which is further exacerbated in an aging population. Since the therapeutic value of imatinib mesylate is limited by such off-target cardiotoxicity, alternative strategies such as nanoformulations are necessary to overcome this problem.

Drug-encapsulated nanoparticles with sustained release properties have been attempted to minimize off-target toxicity of many cancer drugs, ${ }^{15-20}$ including imatinib mesylate. ${ }^{21-23}$ While the nano-encapsulation of imatinib mesylate improves its antitumor activity, ${ }^{23,24}$ it is also demonstrated to minimize the cytotoxicity of the drug to normal cells. ${ }^{21,22}$ Moreover, poly(lactide-co-glycolide) (PLGA) microspheres containing imatinib mesylate inhibited craniopharyngioma-mediated angiogenesis ${ }^{24}$ and intracranial xenograft glioma growth. ${ }^{25,26}$ However, there is no report on the evaluation of cardiotoxicity of imatinib mesylate-loaded nanoparticles so far. Hence, in the current investigation, we have developed and characterized imatinib mesylate-loaded PLGA nanoparticles (INPs) and have evaluated their in vitro cytotoxicity against cancer cells and cardiac toxicity in Wistar rats, in comparison with the free drug.

\section{Materials and methods}

\section{Chemicals and reagents}

Imatinib mesylate was obtained from Ranbaxy Pharmaceuticals (Delhi, India). PLGA (acid-terminated; lactide:glycolide 50:50; Mw [molecular weight] 24,000-38,000 D), polyvinyl alcohol (PVA; Mw 31,000-50,000 D), methylthiazolyldiphenyl-tetrazolium bromide (MTT), dimethylformamide (DMF), and coumarin-6 were purchased from Sigma-Aldrich Co, St Louis, MO, USA. Sodium hydroxide, phosphate buffer, potassium dihydrogen phosphate, methanol, and acetone used in the current study were acquired from Merck Millipore,
Billerica, MA, USA. All reagents used in the present study were of analytical grade.

\section{Preparation and characterization of nanoparticles}

\section{Preparation}

INPs were prepared by emulsion solvent evaporation method. ${ }^{18}$ Briefly, $100 \mathrm{mg}$ PLGA and imatinib mesylate ( $5 \mathrm{mg}$ ) were dissolved in $5 \mathrm{~mL}$ of chloroform. This solution was added drop by drop to the $20 \mathrm{~mL}$ aqueous phase containing 1.5\% PVA and homogenized at 18,000 rpm (IKA T 25 Ultra Turrax ${ }^{\circledR}$ homogenizer). After homogenization, the nano-emulsion was stirred for 3 hours. The resulting emulsion was centrifuged at 20,000 rpm for 15 minutes to pellet down the nanoparticles. The pellet was washed three times with ultra-pure water to remove any free drug. Then, the pellet was freeze-dried and stored at $4^{\circ} \mathrm{C}$ until further use.

\section{Particle size, shape, encapsulation efficiency,} and drug content

Particle size distribution, mean particle size, and zeta potential of INPs were determined in a Zetasizer by dynamic light scattering and laser Doppler anemometry (Zetasizer Nano ZS; Malvern Instruments, Malvern, UK). Briefly, $500 \mu \mathrm{g}$ of INPs was suspended in $1 \mathrm{~mL}$ of deionized water. An electric field of $150 \mathrm{mV}$ was applied to observe the electrophoretic velocity of the particles. All measurements were made at room temperature.

The content of imatinib mesylate in INPs was measured by spectrophotometric assay. Briefly, $10 \mathrm{mg}$ INPs was dissolved in $1 \mathrm{~mL}$ of dichloromethane and $2 \mathrm{~mL}$ phosphate-buffered saline (PBS). The solution was centrifuged at 10,000 rpm, and the supernatant was collected. Absorbance at $265 \mathrm{~nm}$ was read in a spectrophotometer (Shimadzu UV-1700) using PBS as a blank to determine the drug content from a standard graph. ${ }^{27}$ The percentage of encapsulation efficiency (EE\%) and drug content (DC\%) of INPs was determined using the following two formulas:

$$
\begin{aligned}
& \mathrm{EE} \%=\frac{\text { Weight of encapsulated drug }}{\text { Weight of drug used }} \times 100 \\
& \mathrm{DC} \%=\frac{\text { Weight of encapsulated drug }}{\text { Weight of nanoparticles }} \times 100
\end{aligned}
$$

Scanning electron microscopy (SEM) characterized the INPs morphologically. Samples were prepared by dropping INP onto aluminum stubs and allowing them to air-dry. 
The air-dried particles were coated with gold in vacuum using a Fiscon Instrument SC 502 sputter coater and then observed under the SEM (Leica Cambridge S 360; Leica Microsystems, Wetzlar, Germany).

\section{In vitro drug release of nanoparticles}

The in vitro drug release of INPs was carried out using the previously described method with some modifications. ${ }^{28}$ Briefly, $10 \mathrm{mg}$ of INPs was suspended in $2 \mathrm{~mL}$ PBS and transferred into a dialysis bag. The dialysis bag was then placed into a $100 \mathrm{~mL}$ bottle containing $50 \mathrm{~mL}$ PBS and was stirred at $100 \mathrm{rpm}$ at $37^{\circ} \mathrm{C}$. While stirring, $1 \mathrm{~mL}$ PBS sample was withdrawn at different time points from the bottle for 10 days. To maintain the volume, $1 \mathrm{~mL}$ PBS was added to the bottle after each withdrawal. Drug content of each sample was measured spectrophotometrically, as mentioned in the "Particle size, shape, encapsulation efficiency, and drug content" section.

\section{In vitro cytotoxicity studies}

\section{Cancer cell line culture}

Human breast cancer cell line MCF-7 was used in the present study. Cells were maintained in Roswell Park Memorial Institute (RPMI) 1640 medium supplemented with 10\% fetal bovine serum (FBS), $100 \mathrm{U} / \mathrm{mL}$ penicillin, and $100 \mu \mathrm{g} / \mathrm{mL}$ streptomycin (Thermo Fisher Scientific, Waltham, MA, USA) at $37^{\circ} \mathrm{C}$ in a $5 \% \mathrm{CO}_{2}$ humidified incubator.

\section{MTT assay}

The effect of imatinib mesylate in the form of free drug solution and INPs on cell proliferation was determined using MTT assay. MCF-7 cells were plated in flat-bottom 96-well plates at 5,000 cells per well. After incubation for 24 hours at $37^{\circ} \mathrm{C}$, the culture medium was removed and replaced with $100 \mu \mathrm{L}$ fresh medium containing free drug $(0.148,0.295$, 0.59 , and $1.18 \mu \mathrm{g})$, and INPs $(6.56,13.11,26.22$, and 52.44 $\mu \mathrm{g})$; both free drug and INP additions were equivalent to final imatinib concentrations of $2.5,5,10$, and $20 \mu \mathrm{M}$, respectively. Corresponding controls were maintained by adding $100 \mu \mathrm{L}$ medium for free drug control and $100 \mu \mathrm{L}$ medium containing $52.44 \mu \mathrm{g}$ empty nanoparticles for INP control. After 48 hours, medium from the treatments and controls were replaced with $100 \mu \mathrm{L}$ medium containing $50 \mu \mathrm{g}$ MTT and were incubated for 1 hour. Then, $100 \mu \mathrm{L}$ sodium dodecyl sulfate (SDS) solution ( $20 \% \mathrm{w} / \mathrm{v}$, water:DMF at a 1:1 ratio, $\mathrm{pH} 4.7$ ) was added to each well and further incubated for 24 hours to dissolve the formazan crystals formed. The absorbance was read at $570 \mathrm{~nm}$ in an enzyme-linked immunosorbent assay (ELISA) plate reader (Victor 1420;
PerkinElmer Inc, Waltham, MA, USA). The amount of MTT that is converted to formazan after incubation with cells corresponds to the number of viable cells. The half-maximal inhibitory concentration $\left(\mathrm{IC}_{50}\right)$ was determined by nonlinear regression analysis.

\section{Cellular uptake of nanoparticles}

In vitro cellular uptake of nanoparticles was studied using curcumin-loaded PLGA nanoparticles (CNPs). These nanoparticles were prepared essentially as mentioned in the "Preparation and characterization of nanoparticles" section, but using curcumin in the place of imatinib mesylate. MCF-7 cells were seeded in an 8-well ibiTreat microscopy chamber (Ibidi GmbH, Munich, Germany) and allowed to attach and grow. After 24 hours, $150 \mu \mathrm{L}$ medium containing $100 \mu \mathrm{g} / \mathrm{mL}$ CNPs was added to the cells. After 90 minutes, cells were washed, and were replaced with fresh medium. To track the uptake of nanoparticles, the lysosomes of MCF-7 cells were stained with the LysoTracker ${ }^{\circledR}$ Red probe and analyzed under confocal microscope (Axiovert 135M; Zeiss International, Oberkochen, Germany).

\section{Subacute toxicity analyses}

\section{Animals and treatments}

Subacute toxicity of INPs was evaluated in Wister rats weighing about $130-150 \mathrm{~g}$. This study was approved by the Animal Ethical Committee, Padmavathi College of Pharmacy, Tamil $\mathrm{Nadu}$, India. Animals were divided into three groups (group 1, group 2, and group 3), each group containing six adult females. Group 1 received $2 \mathrm{ml}$ PBS and was treated as a control. Group 2 received $2222 \mathrm{mg} / \mathrm{kg}$ INPs (equivalent to $50 \mathrm{mg} / \mathrm{kg}$ imatinib) suspended in PBS. Group 3 received $50 \mathrm{mg} / \mathrm{kg}$ free drug. Treatment for each group was done each day at 9 am, and was done per orally (PO) for 28 days. Throughout the study period, animals were monitored for the development of any toxicological signs and symptoms such as abnormal posture, abnormal movements, difficulties in respiration, and changes in body weight and feed intake.

\section{Hematology and biochemistry}

To know the potential side effects at the cellular level, blood biochemistry and hematological parameters were examined in treated groups of animals and compared with the control group. Blood and serum samples for hematological and biochemical studies were collected from the orbital sinus of each animal in vials rinsed with heparin and vials containing ethylenediaminetetraacetic acid (EDTA), respectively. Hematological analyses include white blood cells (WBCs), 
red blood cells (RBCs), and hemoglobin ( $\mathrm{Hb}$ ) content. The serum samples were analyzed for aspartate aminotransferase (AST), alanine aminotransferase (ALT), and alkaline phosphatase (ALP) to determine possible indication of myocardial damage, if any. All analyses were carried out in a smart lab batch analyzer.

\section{Cardiotoxicity}

Hearts of control and treated animals were collected and observed for gross pathological and weight changes on day 29. For histopathology, heart tissue preserved in $10 \%$ formalin was embedded in paraffin using standard procedures. Sections of $4 \mu \mathrm{m}$ thickness were obtained in a microtome and mounted on glass slides using standard techniques. After staining with hematoxylin and eosin, the slides were examined under a light microscope equipped with photography. Photomicrographs were analyzed for myocardial architecture.

\section{Statistical analysis}

Data were analyzed using GraphPad Prism 5 software (GraphPad Software, Inc, La Jolla, CA, USA). Results are expressed as the mean values \pm standard deviation (SD). Statistical significance between treatments was analyzed by Student's $t$-test. $\mathrm{IC}_{50}$ values were determined by nonlinear curve fitting of $\log$ concentration versus cell viability.

\section{Results and discussion \\ Characterization of INPs}

We have nano-encapsulated imatinib mesylate within the biodegradable, US Food and Drug Administration (FDA)-approved PLGA polymer. ${ }^{5}$ Moreover, PLGA nano-encapsulation is known to reduce the subacute toxicity, including cardiotoxicity of doxorubicin and erlotinib. ${ }^{17,18}$

\section{Particle size distribution}

Nanoparticle size is one of the most important characteristics, as it regulates the biological fate, toxicity, targeting ability, as well as drug loading, drug release, and stability of the formulation. ${ }^{29}$ Particle size distribution of the INPs is shown in Figure 1. The average diameter of INPs ranged between 250 and $300 \mathrm{~nm}$, with a polydispersity index of 0.20 . Zeta potential is an important characteristic for nanoparticles, as surface charge directly controls the aggregation behavior of the particles. The lowest zeta potential $(-10.6 \mathrm{mV})$ indicated that the INPs were physically stable.

\section{Shape of nanoparticles}

A SEM image of INPs is shown in Figure 2. From the results, it is clear that the nanoparticles have a smooth spherical shape. Their smooth surface reveals the complete removal of solvent from the formulated nanoparticles, indicating their good quality. ${ }^{30}$

\section{Encapsulation efficiency, drug content, and in vitro drug release}

The encapsulation efficiency of the nanoparticles was found to be $89.94 \%$. The drug content of the nanoparticles was $2.25 \%$ (0.0225 mg/mg INPs).

As graphically illustrated in Figure 3, the release of imatinib mesylate from the INPs occurred in a biphasic manner, with an initial burst phase followed by a diffusion-controlled slower release phase, as previously reported. ${ }^{25}$ Soon after 6 hours and 48 hours, about $40 \%$ and $60 \%$ of the encapsulated drug was

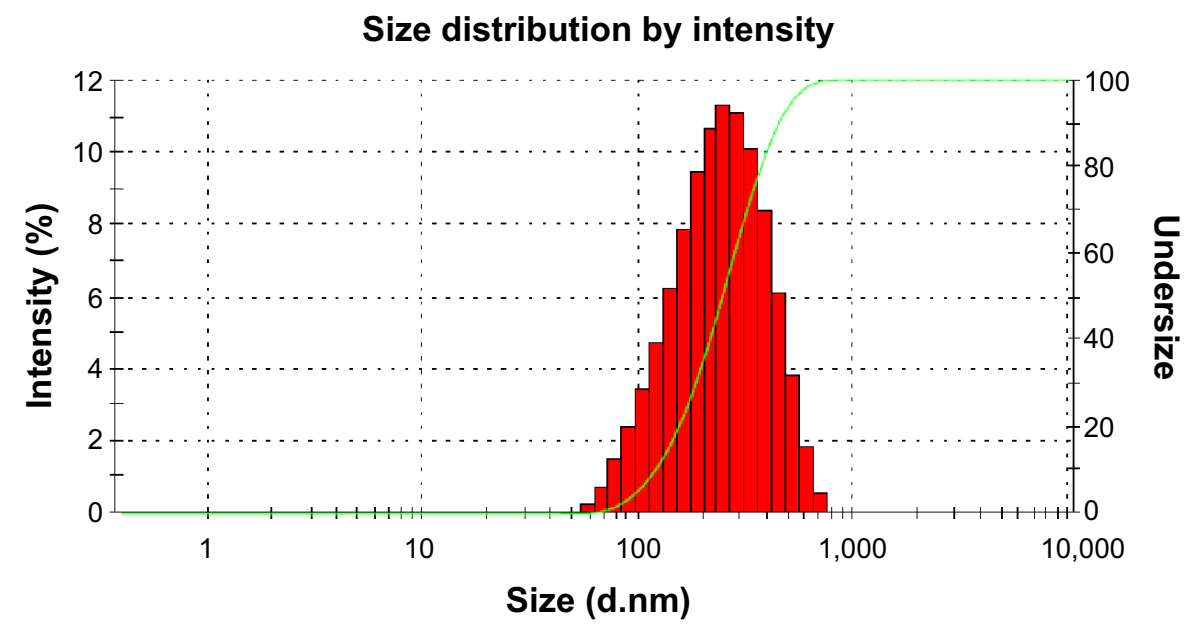

Figure I Histogram showing the particle size and size distribution of INPs.

Abbreviation: INPs, imatinib mesylate-loaded poly(lactide-co-glycolide) nanoparticles. 


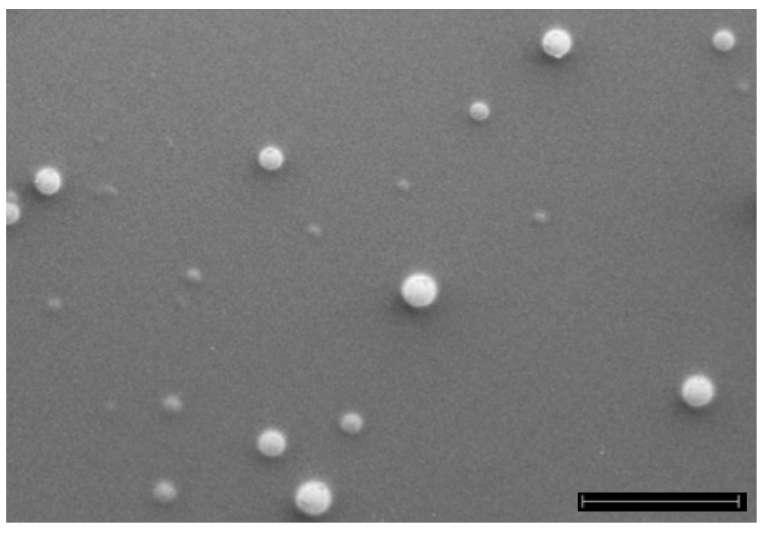

Figure 2 Scanning electron microscopic image of INPs (scale bar $=2 \mu \mathrm{m}$ ). Abbreviation: INPs, imatinib mesylate-loaded poly(lactide-co-glycolide) nanoparticles.

released, respectively, and this initial burst can be attributed to the drug molecules adhering to the nanoparticle surface. As the hydrophilicity of PLGA nanoparticles enables an extensive water penetration to the polymeric matrix, a significant amount of drug release happens during the initial days of incubation in aqueous buffer. The initial burst was followed by a gradual rise and reached $70 \%$ on day 10 , indicating a sustained release phase. Similar in vitro release kinetics of fluorescein isothiocyanate-loaded polyethylene glycol-PLGA nanoparticles, eg, approximately $40 \%$ on day 1 and a sustained release over the next 28 days has been previously demonstrated. ${ }^{21}$

\section{Internalization of nanoparticles by cancer cells}

Fluorescent images of MCF-7 cells co-incubated with CNPs for 90 minutes and stained with LysoTracker Red taken

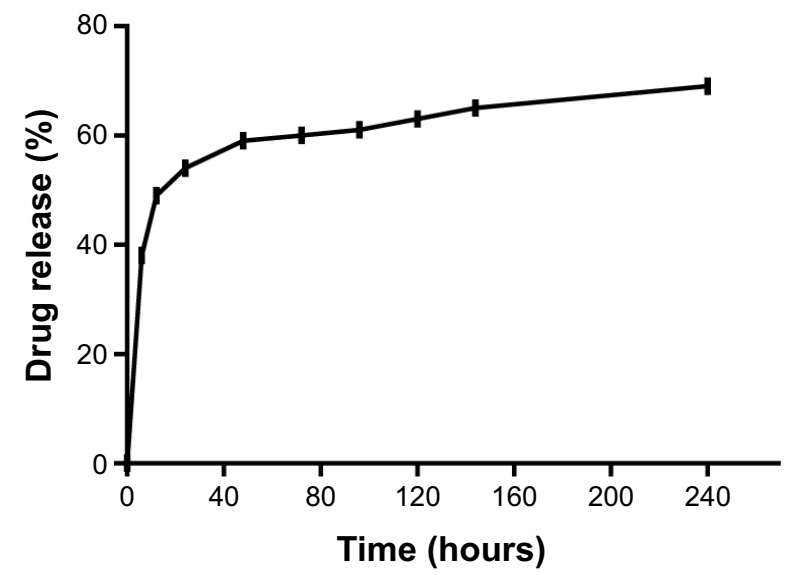

Figure 3 In vitro drug release characteristics of INPs, showing a biphasic profile, an initial burst release up to 24 hours, and then an extended release over 10 days. Abbreviations: INPs, imatinib mesylate-loaded poly(lactide-co-glycolide) nanoparticles. under red filter (Figure 4A) and green filter (Figure 4B), respectively, show the localization of lysosomes and CNPs. The merged image (Figure 4C) clearly shows that the CNPs are colocalized within the lysosomes, indicating their internalization by endocytosis.

\section{Cytotoxicity of imatinib mesylate in the form of free drug and INPs}

MTT-based cell proliferation assay results of MCF-7 cells revealed that cell viability was reduced with increasing concentrations of INPs or free drug (Figure 5). However, INPs consistently showed higher viability reduction than equivalent free drug in all the concentrations tested. No cytotoxicity was observed in cells treated with just medium (free drug control) and empty nanoparticles (INP control). The $\mathrm{IC}_{50}$ value for INPs was found to be $2.6 \mu \mathrm{M}$ at 48 hours, which was 2.9 times less than imatinib mesylate solution.

\section{In vivo toxicity study}

The results of hematological, biochemical, and heart weight analyses of rats administered with imatinib mesylate in the form of free drug $(50 \mathrm{mg} / \mathrm{kg})$ and INPs $(2.222 \mathrm{~g} / \mathrm{kg})$ are summarized in Table 1.

\section{Hematology}

Although the WBC, $\mathrm{RBC}$, and $\mathrm{Hb}$ content were reduced both in the nanodrug- and free drug-treated animals compared to the control group, the changes were not statistically significant for INPs. However, there was a significant decrease in the $\mathrm{WBC}, \mathrm{RBC}$, and $\mathrm{Hb}$ count of free drug-treated animals (Table 1), indicating the development of anemia and reduction of immunity in these animals.

\section{Biochemistry}

ALT, AST, and ALP are liberated into the blood after extensive tissue injury; in particular, elevated levels of AST are associated with heart muscle injury. ${ }^{31}$ Biochemical analysis of AST, ALT, and ALP levels in the serum samples did not show any significant change between control and nanodrug treated groups. Nevertheless, an increased level of these enzymes was observed in the animals administered with free drug compared to control (Table 1), indicating tissue damage, including myocardial damage.

\section{Heart weight}

Heart weight was significantly increased due to heart inflammation in free drug-treated animals over INP-treated 

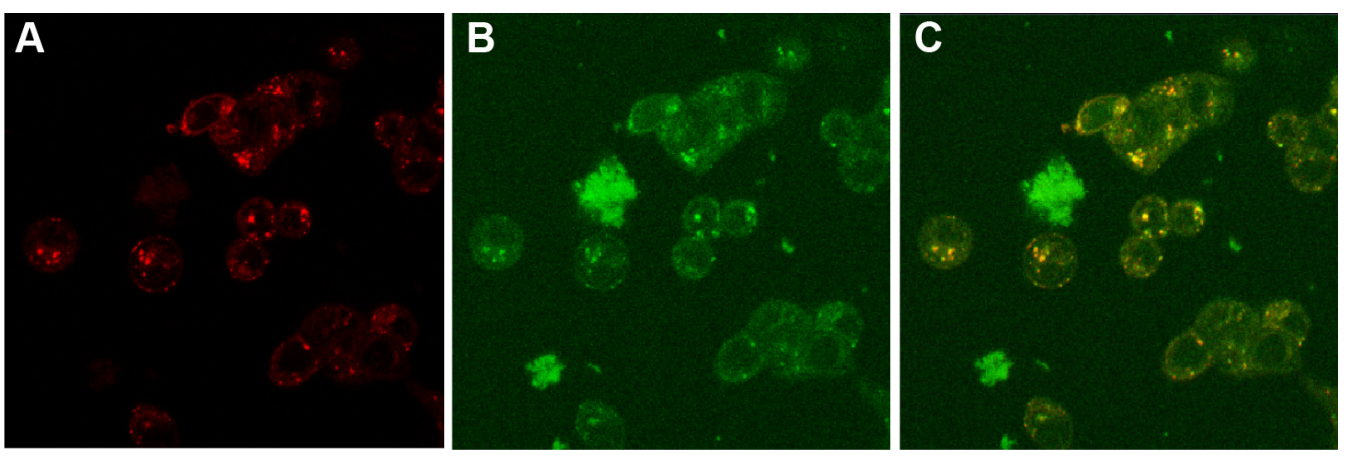

Figure 4 Internalization of CNPs.

Notes: (A) Red fluorescence from LysoTracker ${ }^{\circledR}$ Red showing lysosomes and acidic vesicles; (B) green fluorescence from curcumin showing intracellular localization of CNPs; (C) overlap image of both figures (A and $\mathbf{B}$ ) resulted in yellow spots showing that CNPs are in the lysosomes, and acidic vesicles of mature endosomes. Abbreviation: CNPs, curcumin-loaded poly(lactide-co-glycolide) nanoparticles.

animals and control animals. However, no significant change was noticed between INP-treated and control animals (Table 1).

\section{Cardiac histopathology}

Histopathological analysis of heart sections from INPadministered animals (Figure 6C and D) revealed no significant toxicity-related changes compared to the controls (Figure 6A and B). This is in agreement with the fact that nano-encapsulation reduces drug-induced off-target cardiotoxicity of many drugs such as doxorubicin ${ }^{15,20}$ and epirubicin. ${ }^{19}$ In addition, nano-encapsulation also improves the drug's antitumor activity ${ }^{17}$ by making the tumor cells more sensitive to the drug. ${ }^{16}$ In this line of research, using CML stem cells, Palamà et al have reported that packaging of imatinib mesylate into a biodegradable carrier based on polyelectrolyte microcapsules increased the drug's retention

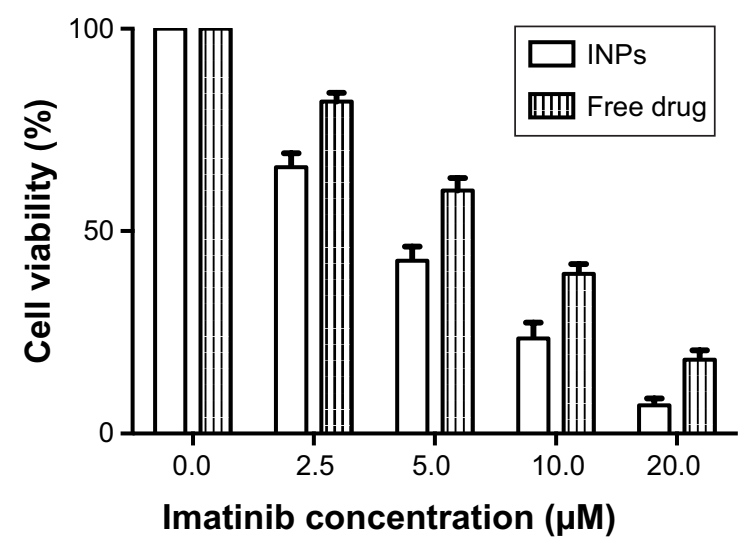

Figure $\mathbf{5}$ MTT assay results showing higher cytotoxicity of INPs compared to free imatinib mesylate. Imatinib concentration of $0.0 \mu \mathrm{M}$ represents respective controls of INPs and free drug, which showed 100\% cell viability.

Abbreviations: INPs, imatinib mesylate-loaded poly(lactide-co-glycolide) nanoparticles; MTT, methylthiazolyldiphenyl-tetrazolium bromide. effects and antitumor activity, while improving the ex vivo purging of malignant progenitors from patient autografts. ${ }^{24}$ Both the reduction in off-target cardiotoxicity and increased antitumor activity could be attributed to the gradual release of imatinib mesylate, or reduced exposure of imatinib mesylate to the heart tissue, as it is encapsulated inside the nanoparticles. ${ }^{32}$

In the case of rats administered with free imatinib mesylate, loss of normal architecture and damage to cardiac muscle fibers were observed (Figure 6E and F), which is consistent with its previously reported semi-targeting property and heart toxicity, ${ }^{13,33}$ even at low concentrations. ${ }^{12}$ Imatinib mesylatecaused cardiotoxicity manifests cardiac mitochondrial dysfunction, ventricular dysfunction, and mild myocardial lesions..$^{21,34}$

\section{Conclusion}

In spite of many reports on nanoformulations of anticancer drugs, very few studies are available on the in vivo toxicity of nanoparticles. Here, we have demonstrated that PLGA

Table I Subacute in vivo toxicity analyses of rats after 28 days

\begin{tabular}{|c|c|c|c|}
\hline Parameters & Control & INPs & Free drug \\
\hline WBCs $\left(10^{9} / \mathrm{L}\right)$ & $11.49 \pm 0.20$ & $11.35 \pm 0.23$ & $10.43 \pm 1.02 *$ \\
\hline RBCs $\left(10^{12} / L\right)$ & $7.36 \pm 0.35$ & $7.06 \pm 0.36$ & $6.38 \pm 0.88 *$ \\
\hline $\mathrm{Hb}(\mathrm{g} / \mathrm{L})$ & $|2.8| \pm 0.5 \mid$ & $12.22 \pm 1.19$ & $\mathrm{II} .06 \pm 0.8 \mathrm{I} * *$ \\
\hline AST (U/L) & $118.50 \pm 4.54$ & $121.66 \pm 2.80$ & $129.83 \pm 2.13^{* *}$ \\
\hline ALT (U/L) & $51.08 \pm 2.37$ & $52.33 \pm 1.86$ & $58.50 \pm 3.39 * *$ \\
\hline ALP (U/L) & $111.66 \pm 3.20$ & $111.33 \pm 3.32$ & II $8.66 \pm 4.63 *$ \\
\hline Heart weight (g) & $0.66 \pm 0.02$ & $0.65 \pm 0.01$ & $0.7 I \pm 0.04^{*}$ \\
\hline
\end{tabular}

Notes: Statistically significant differences from controls $(* P<0.05 ; * * P<0.01$; $* * * P<0.001)$, using Student's $t$-test. Data are presented as mean $\pm S D$ of three replications.

Abbreviations: SD, standard deviation; INPs, imatinib mesylate-loaded poly(lactideco-glycolide) nanoparticles; WBCs, white blood cells; RBCs, red blood cells; $\mathrm{Hb}$, hemoglobin; AST, aspartate aminotransferase; ALT, alanine aminotransferase; ALP, alkaline phosphatase. 

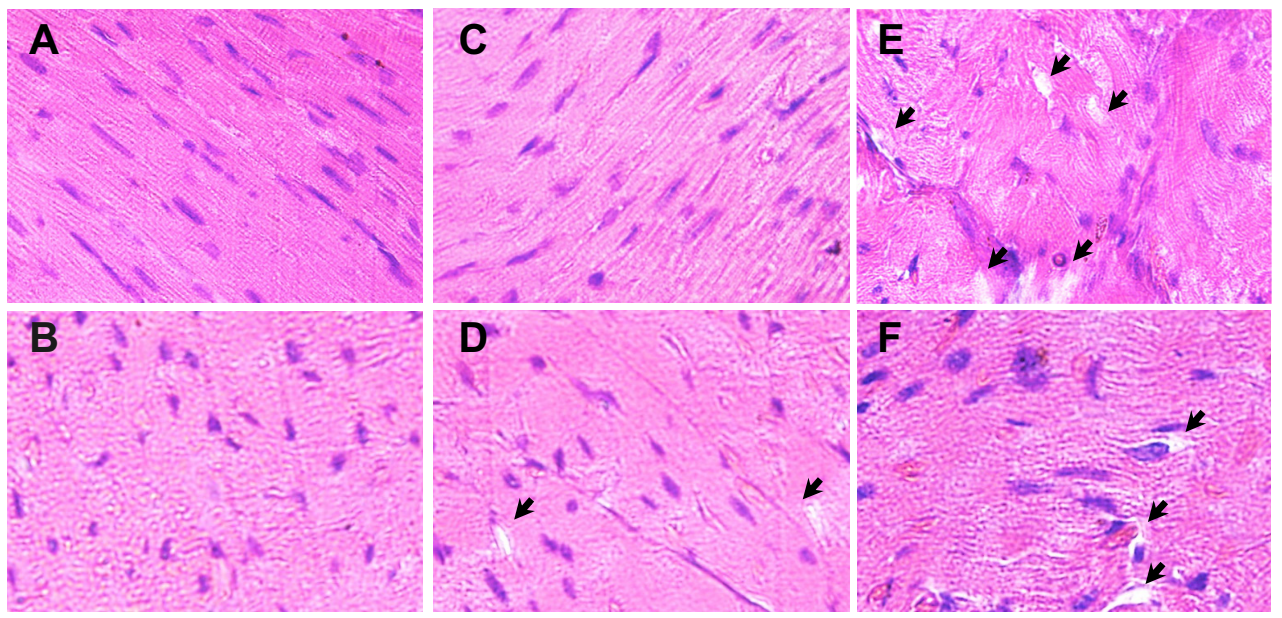

Figure 6 Histopathology of myocardium from experimental animals. Representative images of left ventricular histology from experimental animals stained with hematoxylin and eosin are shown.

Notes: (A, B) The cardiac myofibrils from control rats exhibited regular arrangement of thick and thin myofilaments. (C, D) INP treatment did not alter the morphology of myocardium of rats significantly, although very few isolated vacuoles are present. (E, F) Myofibrillar loss and formation of variable-sized cytoplasmic vacuoles in the myocardium of rats treated with $50 \mathrm{mg} / \mathrm{kg}$ dose of free imatinib mesylate. Vacuole structures are indicated with black arrows.

Abbreviation: INP, imatinib mesylate-loaded poly(lactide-co-glycolide) nanoparticle.

nano-encapsulation significantly reduces drug-induced cardiotoxicity of imatinib mesylate. Likewise, erlotinib-, epirubicin-, and doxorubicin-induced cardiotoxicity have also been significantly reduced by nano-encapsulation of these drugs with PLGA or polyethylene glycol-PLGA. ${ }^{17-19,35}$ Extensive studies in terms of acute and chronic toxicity, and pharmacokinetic and pharmacodynamic effects of imatinib mesylate are necessary to understand the mechanisms behind the reduced cardiac toxicity and the long-term effects of INPs.

\section{Acknowledgments}

GM and CJS were supported by the Fundação para a Ciência e a Tecnologia (FCT), Portugal, by grants SFRH/ BD/72809/2010 and SFRH/BPD/89493/2012, respectively. The present work was also supported by the FCT projects PTDC/AGR-GPL/119211/2010 and UID/AGR/04033/2013. We would like to thank Dr Palanivel, Assistant Professor, Department of Pharmacology, Padmavathi College of Pharmacy, Tamil Nadu, India for help with animal studies.

\section{Disclosure}

The authors report no conflicts of interest in this work.

\section{References}

1. Sheeba CJ, Marslin G, Revina AM, Franklin G. Signaling pathways influencing tumor microenvironment and their exploitation for targeted drug delivery. Nanotechnol Rev. 2014;3(2):123-151.

2. Druker BJ, Tamura S, Buchdunger E, et al. Effects of a selective inhibitor of the Abl tyrosine kinase on the growth of Bcr-Abl positive cells. Nat Med. 1996;2(5):561-566.
3. Carroll M, Ohno-Jones S, Tamura S, et al. CGP 57148, a tyrosine kinase inhibitor, inhibits the growth of cells expressing BCR-ABL, TEL-ABL, and TEL-PDGFR fusion proteins. Blood. 1997;90(12):4947-4952.

4. Heinrich MC, Griffith DJ, Druker BJ, Wait CL, Ott KA, Zigler AJ. Inhibition of c-kit receptor tyrosine kinase activity by STI 571, a selective tyrosine kinase inhibitor. Blood. 2000;96(3):925-932.

5. Danhier F, Ansorena E, Silva JM, Coco R, Le Breton A, Préat V. PLGA-based nanoparticles: an overview of biomedical applications. $J$ Control Release. 2012;161(2):505-522.

6. Elias MH, Baba AA, Azlan H, et al. BCR-ABL kinase domain mutations, including 2 novel mutations in imatinib resistant Malaysian chronic myeloid leukemia patients-Frequency and clinical outcome. Leuk Res. 2014;38(4):454-459.

7. Din OS, Woll PJ. Treatment of gastrointestinal stromal tumor: focus on imatinib mesylate. Ther Clin Risk Manag. 2008;4(1):149-162.

8. Andrae J, Gallini R, Betsholtz C. Role of platelet-derived growth factors in physiology and medicine. Genes Dev. 2008;22(10):1276-1312.

9. Lennartsson J, Rönnstrand L. Stem cell factor receptor/c-Kit: from basic science to clinical implications. Physiol Rev. 2012;92(4): 1619-1649.

10. Raines EW. PDGF and cardiovascular disease. Cytokine Growth Factor Rev. 2004;15(4):237-254.

11. Force T, Krause DS, Van Etten RA. Molecular mechanisms of cardiotoxicity of tyrosine kinase inhibition. Nat Rev Cancer. 2007;7(5): 332-344.

12. Herman EH, Knapton A, Rosen E, et al. A multifaceted evaluation of imatinib-induced cardiotoxicity in the rat. Toxicol Pathol. 2011;39(7): 1091-1106.

13. Kerkelä R, Grazette L, Yacobi R, et al. Cardiotoxicity of the cancer therapeutic agent imatinib mesylate. Nat Med. 2006;12(8): 908-916.

14. Maharsy W, Aries A, Mansour O, Komati H, Nemer M. Ageing is a risk factor in imatinib mesylate cardiotoxicity. Eur J Heart Fail. 2014;16(4): 367-376.

15. Chen $Y$, Yang W, Chang B, Hu H, Fang X, Sha X. In vivo distribution and antitumor activity of doxorubicin-loaded $\mathrm{N}$-isopropylacrylamideco-methacrylic acid coated mesoporous silica nanoparticles and safety evaluation. Eur J Pharm Biopharm. 2013;85(3 Pt A):406-412.

16. Maksimenko A, Mougin J, Mura S, et al. Polyisoprenoyl gemcitabine conjugates self assemble as nanoparticles, useful for cancer therapy. Cancer Lett. 2013;334(2):346-353. 
17. Mao JN, Li AJ, Zhao LP, et al. PEG-PLGA nanoparticles entrapping doxorubicin reduced doxorubicin-induced cardiotoxicity in rats. $A d v$ Mat Res. 2014;912:263-268.

18. Marslin G, Sheeba CJ, Kalaichelvan VK, Manavalan R, Reddy PN, Franklin G. Poly(D,L-lactic-co-glycolic acid) nanoencapsulation reduces Erlotinib-induced subacute toxicity in rat. J Biomed Nanotechnol. 2009;5(5):464-471.

19. Nasr M, Nafee N, Saad H, Kazem A. Improved antitumor activity and reduced cardiotoxicity of epirubicin using hepatocyte-targeted nanoparticles combined with tocotrienols against hepatocellular carcinoma in mice. Eur J Pharm Biopharm. 2014;88(1):216-225.

20. Yuan A, Wu J, Song C, et al. A novel self-assembly albumin nanocarrier for reducing doxorubicin-mediated cardiotoxicity. J Pharm Sci. 2013;102(5):1626-1635.

21. Kimura S, Egashira K, Nakano K, et al. Local delivery of imatinib mesylate (STI571)-incorporated nanoparticle ex vivo suppresses vein graft neointima formation. Circulation. 2008;118(14 Suppl):S65-S70.

22. Mendonca LS, Moreira JN, de Lima MC, Simões S. Co-encapsulation of anti-BCR-ABL siRNA and imatinib mesylate in transferrin receptortargeted sterically stabilized liposomes for chronic myeloid leukemia treatment. Biotechnol Bioeng. 2010;107(5):884-893.

23. Thampi RG, Godwin SE, Harish G. Design and characterization of nanoparticulate drug delivery system of an anticancer drug: Imatinib mesylate. Indian J Res Pharm Biotech. 2014;1082-1087.

24. Palamà IE, Leporatti S, de Luca E, et al. Imatinib-loaded polyelectrolyte microcapsules for sustained targeting of BCR-ABL+ leukemia stem cells. Nanomedicine (Lond). 2010;5(3):419-431.

25. Karal-Yilmaz O, Ozkan A, Akgun E, et al. Controlled release of imatinib mesylate from PLGA microspheres inhibit craniopharyngioma mediated angiogenesis. J Mater Sci Mater Med. 2013;24(1):147-153.
26. Benny O, Menon LG, Ariel G, et al. Local delivery of poly lactic-co-glycolic acid microspheres containing imatinib mesylate inhibits intracranial xenograft glioma growth. Clin Cancer Res. 2009;15(4):1222-1231.

27. Sikharam S. Release Kinetics of Imatinib Mesylate from a Thermosensitive Polymer and its Effect on Vascular Smooth Muscle Cells [dissertation]. Salt Lake City: The University of Utah; 2011.

28. Fan Y, Du W, He B, et al. The reduction of tumor interstitial fluid pressure by liposomal imatinib and its effect on combination therapy with liposomal doxorubicin. Biomaterials. 2013;34(9):2277-2288.

29. Zhang XD, Wu D, Shen X, et al. Size-dependent in vivo toxicity of PEGcoated gold nanoparticles. Int J Nanomedicine. 2011;6:2071-2081.

30. Kaleemuddin M, Srinivas P. Lyophilized oral sustained release polymeric nanoparticles of nateglinide. AAPS Pharm Sci Tech. 2013;14(1): $78-85$.

31. Karmen A, Wroblewski F, and La Due JS. Transaminase activity in human blood. J Clin Invest. 1955;34(1):126-131.

32. Kalaria DR, Sharma G, Beniwal V, Ravi Kumar MN. Design of biodegradable nanoparticles for oral delivery of doxorubicin: in vivo pharmacokinetics and toxicity studies in rats. Pharm Res. 2009;26(3): $492-501$.

33. Lee SJ, Wang JY. Exploiting the promiscuity of imatinib. J Biol. 2009; 8(3):30.

34. Saad SY, Alkharfy KM, Arafah MM. Cardiotoxic effects of arsenic trioxide/imatinib mesilate combination in rats. J Pharm Pharmacol. 2006;58(4):567-573.

35. Jain AK, Swarnakar NK, Das M, et al. Augmented anticancer efficacy of doxorubicin-loaded polymeric nanoparticles after oral administration in a breast cancer induced animal model. Mol Pharm. 2011;8(4): 1140-1151.
International Journal of Nanomedicine

\section{Publish your work in this journal}

The International Journal of Nanomedicine is an international, peerreviewed journal focusing on the application of nanotechnology in diagnostics, therapeutics, and drug delivery systems throughout the biomedical field. This journal is indexed on PubMed Central, MedLine, CAS, SciSearch ${ }^{\circledR}$, Current Contents ${ }^{\circledR} /$ Clinical Medicine,

\section{Dovepress}

Journal Citation Reports/Science Edition, EMBase, Scopus and the Elsevier Bibliographic databases. The manuscript management system is completely online and includes a very quick and fair peer-review system, which is all easy to use. Visit http://www.dovepress.com/ testimonials.php to read real quotes from published authors. 